\title{
СИЛУРИЙСКИЕ ОСТРАКОДЫ В РАЗРЕЗЕ СКВАЖИНЫ OXECAAPE
}

Скважина Охесааре, пробуренная в 1960-1961 гг. на западном побережье полуострова Сырве о. Сааремаа, впервые на территории Әстонии вскрыла почти полный разрез ордовика и силура. Предварительные данные о силурийском разрезе этой скважины приведены в статье А. Аалоэ и Д. Кальо (1962). В течение ряда лет керн скважины подвергался тщательному литологическому и палеонтологическому изучению, основные результаты которого суммированы в монографии «Силур Әстонии» (Кальо и др., 1970).

В данной статье изложены результаты изучения остракод из керна скв. Охесааре с целью выявления закономерностей их распределения в силуре Эстонии и стратиграфического значения этой группы фауны. Распространение видов в данном разрезе сравнивается с их распространением в разрезах некоторых других скважин и областей выхода.

Силурийские отложения вскрыты скв. Охесааре в интервале 1,75437,7 м (см. Аалоэ, Кальо, 1962; Кальо и др., 1970)*. В разрезе представлены почти все горизонты силура за исключением верхов каугатумаского горизонта мощностью около 3 , а также охесаареского горизонта. Для полноты картины распространения остракод изучались еще образцы из верхов каугатумаского горизонта из разреза неглубокой скв. Охесааре 2, расположенной в южной части берегового обрыва Охесааре, около 150 м севернее скв. Охесааре, а также с берегового обрыва, где почти полностью обнажается охесаареский горизонт. Всего было обработано 230 образцов из керна скв. Охесааре, 26 - из скв. Охесааре 2 и 25 - с берегового обрыва, каждый весом 200-500 г. Опробованию подвергались главным образом глинистые прослои, которые содержат больше остракод и легче обрабатываются.

В ордовикских отложениях разреза скв. Охесааре на глубине $43 \bar{\imath}, 7$-520,4 м остракоды обнаружены только в редких образцах, так как породы этого возраста значительно доломитизированы. Непосредственно ниже границы ордовика и силура на глубине $437,7-449,6$ м найдены Silenis sp., Rectella sp.,Microcheilinella sp. и в одном из образцов с глубины 444,5 м - Bollia mezvagarensis Gailite (Гайлите, 1970). Последний вид встречен в Западной Латвии в кулдигской пачке, т. е. в аналогах верхнеордовикского поркуниского горизонта.

Силурийские отложения в разрезе скв. Охесааре содержат довольно богатую и разнообразную фаунулу остракод, которую в общих чертах

* По распространению кислотоустойчивых микрофоссилий к силуру относится еще интервал $437,7-445,9$ м (частное сообщение Р. Мянниля).

5 ENSV TA Toimetised K* G-4 1971 
можно разделить на лландоверийскую, венлокскую и лудловско-даунтонскую ассоциации видов.

Лландоверийская ассоциация остракод (рис. 1) в керне скв. Охесааре относительно бедная. Она состоит только из 15 видов, многие из которых представлены малым количеством особей довольно плохой сохранности.

В юуруском горизонте $\left(\mathrm{G}_{1-2}\right)$ наряду с некоторыми переходящими в лландовери ордовикскими формами (Silenis sp., Pseudorayella tersa Neckaja) найдены новые виды из родов Rectella, Altha и Bythocyprot. dea. Последние свойственны этому горизонту и в других разрезах Эстонии. Bythocyproidea sp. n. распространяется в разрезе скв. Охесаape также и в райккюласком горизонте, но в других разрезах он замещается близким ему видом Bythocyproidea sarvi Neckaja.

Общие для юуруского и р айккюл а ского $\left(\mathrm{G}_{3}\right)$ горизонтов внды Silenis estonus Neckaja и Polyzygia estonica Neckaја появляются в охесаареском разрезе лишь в верхах юуруского горизонта. Поздно встречаются и Altha modesta Neckaja и Paraparchites tenuicostatus Neckaja, имеющие обычно более широкое вертикальное распространение. Microcheilinella mobile Gailite, который до сих пор был известен только из юуруского горизонта, распространяется здесь в виде редких особей только в райккюласком горизонте.

Верхняя граница райккюлаского горизонта в данном разрезе по остракодам выявляется нечетко. Она установлена на глубине $372,6 \mu$, непосредственно ниже этого уровня распространяются Bythocyproideu sp. п. и Microcheilinella ovata (Neckaja), но остальные юуруско-райккюлаские виды - Silenis estonus, Polyzygia estonica, а также Microcheilinella mobile - не встречены в верхней 10-метровой толще горизонта.

Ад а в ерески й го ри зонт (Н) разреза скв. Охесааре содержит весьма малочисленный комплекс остракод. Кроме характерных всему лландовери видов Paraparchites tenuicostatus Neckaja, Neoprimitiella litviensis (Neckaja) и Altha modesta (Neckaja), здесь встречен еще Microcheilinella semibulbosa (Neckaja), который, по всей вероятности, также относится к группе упомянутых вндов. Кроме того, здесь найдены Longiscella caudalis (Jones) и Thlipsuroides walensis (Krandijevski). Longiscella caudalis впервые описан из глинистых известняков, содержащих Arachnophydlum около Висбю на о. Готланд, т. е. из отложений, подстилающих нижневисбюские слои. Согласно материалам автора, собранным в 1962 г., а также работам В. Крандиевского (1963) и А. Абушик (1968), этот вид вместе с Thlipsuroides walensis распространяется в рестевских слоях китайгородского горизонта Подолии, точнее, по нашим данным, - в самой нижней части рестевских слоев у с. Китайгород и Дурняковцы и, по всей вероятности, в той части разреза, которую П. Цегельнюк (1969) по брахиоподам и граптолитам считает отложениями лландоверийского возраста. В Прибалтике Thlipsuroides walensis вместе с другими лландоверийскими видами встречен еще в разрезах скважин Пярну (гл. 124,3 м) и Икла $(290,0-296,5$ м) Южной Эстонии и в разрезе скв. Калвария Южной Литвы $(845,5-847,7$ м). Longiscella caudalis, очевидно, распространяется и в венлокских отложениях.

В верхах адавереского горизонта встречены еще Silenis subtriangulatus Neckaja и Parabolbina sp. п., бо́льшее количество особей которых распространяется в отложениях венлокского возраста рассматриваемого разреза.

Венлокские отложения в разрезе скв. Охесааре содержат весьма разнообразную ассоциацию видов остракод, число которых достигает 40. 
Особенно часто и большим количеством особей представлены здесь виды с широким диапазоном распространения - Silenis subtriangulatus Neckaja, Birdsalella cornuta Krause, Altha lata Neckaja и разные виды из рода Microcheilinella, а также Bollia amabilis Neckaja, Eoprimitia ? versipella Neckaja и другие характерные всему венлоку Балтийского бассейна виды. Наряду с ними постепенно появляются новые виды остракод, многие из которых исчезают в конце венлока (см. рис. 1). Поэтому, судя по остракодам, граница яаниского и яагарахуского горизонтов не резкая и прослеживается только по некоторым типичным для яагарахуского горизонта видам: Beyrichia hellviensis, Triemilomatella prisca и др.

Я аниский го ризонт $\left(\mathrm{J}_{1}\right)$ разреза Охесааре по остракодам делится на две части. В нижней, охватывающей тыллаские слои и низы парамаяских слоев, среди других видов остракод встречены Pseudobollia krekenawaiensis Neckaja, Leperditella? conspecta Neckajа и Primitiopsella rectellaformis Neckaja, массовое распространение которых, повидимому, ограничивается этой частью горизонта. Только в верхней части яаниского горизонта встречены Clavofabella juvenca Sarv, Craspedobolbina (Odoniobolbina) sp. и Craspedobolbina insulicola Martinsson. Последний вид известен из нижней части слоев Слите и его ограниченное определенным интервалом распространение в разрезе Охесааре способствует корреляции соответствующих частей разрезов на островах Готланд и Сааремаа. K названным выше видам добавляется довольно хорошо представленный новый элемент остракод, появляющийся в верхней части яаниского горизонта, но продолжающий распространяться и в яагарахуском горизонте рассматриваемого разреза. Нанболее характерны для этого элемента Thlipsura corpulenta Jones et Holl, Undulirete? sp. n., Aechmina bovina Jones, Clavofabella reticristata (Jones).

Я а г а рах у ском у го р и зон т у $\left(\mathrm{J}_{2}\right)$ в разрезе скв. Охесааре харак. терна группа бейрихиацей и примитиопсид, в том числе Craspedobolbina. cuspidulata Martinsson, Craspedobolbina cf. lembodes Martinsson, Beyrichia hellviensis Martinsson, Clavofabella extenta Sarv, C. incurvata Martinsson и др. Распространение многих видов ограничивается нижней частью яагарахуского горизонта - в маазиских и сайкласких слоях они не обнаружены. В верхах горизонта (сайклаские слои) появляется новый элемент фауны остракод, состоящий из 8 видов (Leiocyamus apicatus Martinsson, Beyrichia subornata Martinsson, Lichwinia ? silurica Neckaja, Bolbiprimitia inaequalis (Jones) и др.), часть из которых переходит в отложения лудловского яруса рассматриваемого разреза.

Сопоставление венлокских отложений Северной Прибалтики, о. Готланд и Подолии по остракодам производилось в нашей предыдущей работе (Сарв, 1968), а также А. Мартинссоном (Martinsson, 1967), А. Абушик (1968) и Д. Кальо и др. (1970). Здесь нет необходимости вдаваться в детальный анализ этих работ, поскольку корреляционные вопросы трактуются в них более или менее согласованно. Поэтому можно резюмировать, что яанискому горизонту соответствуют на о. Готланд слои Верхний Висбю, Хёгклинт, Тофта и нижняя часть слоев Слите, а в ІІодолии верхняя часть рестевских слоев, демшинские и марьяновские слои китайгородского горизонта; яагарахускому горизонту соответствуют на о. Готланд средняя и верхняя части слоев Слите и слои Халла-Мульде, а в Подолии - черченские слои китайгородского горизонта и мукшинский горизонт.

Распространение остракод в верхнесилурийских отложениях разреза Охесааре мало отличается от их распространения в обнажениях и раз- 
резах других скважин. Как на выходе, так и здесь, в паадласком горизонте появляется совершенно новый видовой и, частично, родовой комплекс остракод, который несколько пополняется еще в курессаареском и каутатумаском горизонтах (см. рнс. 2). Различия заключаются в отсутствии некоторых видов в разрезе Охесааре или в наличии таких видов, которые известны только по керну этой скважины.

В отложениях роотсикюлаского горизонта $\left(\mathrm{K}_{1}\right)$ разреза Oxесааре остракоды, кроме Beyrichia subornata (в низах горизонта) и Leiocyamus apicatus, не обнаружены. Упомянутые виды установлены в слоях Мульде на о. Готланд, они встречены также в верхней части яага. рахуского горизонта в разрезе скв. Охесааре.

Остракоды отсутствуют и в нижних слоях па адлаского гори 3 о н т $\left(\mathrm{K}_{2}\right)$ в интервале $115-118,4$, которые, как и весь роотсикюлаский горнзонт, представлены главным образом доломитистыми известняками и доломитами. Выше по разрезу встречен довольно богатый комплекс остракод, состоящий из 28 видов. 10 из них (Amygdabella subclusa Martinsson, Cytherellina magna (Neckaja), Kuresaaria circulata (Neckaja) и др.) появляются на разных уровнях горизонта и относятся к категории видов широкого вертикального распространения. 16 видов характерны только паадласкому горизонту. Из них 5 (Neobeyrichia nutans Martinsson, Beyrichia grogarniana Martinsson, B. eteliana Martinsson, Lophoctenella angustilaqueata Martinsson и Loella ? sp. n.) известны в Северной Прибалтике только по материалам разреза Охесааре. Из остальных 11 паадласких видов чаще всего в этом разрезе встречаются Hemsiella hemsiensis Martinsson, Amygdalella paadlaensis Sarv, Moorea bisulcata (Kolmodin) и Berolinella praevia Sarv, а остальные, в первую очередь Hammariella pulchrivelata Martinsson, Gannibeyrichia gannensis Martinsson, Clavofabella nodosa Sarv и др., - относительно редко.

Из рис. 2 явствует, что только в саувереских слоях $\left(\mathrm{K}_{2} \mathrm{~S}\right)$ распространяется 8 видов остракод (Amygdalella paadlaensis, Clavofabella helerosa, Moorea bisulcata, Hammariella pulchrivelata и др.), которые по материалам из обнажений встречаются обычно в более высоких слоях. Данное обстоятельство говорит о том, что эти виды появились несколько раньше в удаленной от берега более глубоководной части бассейна.

Подавляющее большинство видов бейрихийд и краспедоболбинид, найденных в паадласком горизонте разреза Охесааре, известны из слоев Хемсе на о. Готланд. Паадлаский и хемсеский комплексы, в свою очередь, сопоставимы с комплексом остракод малиновецкого горизонта Подолии (Абушик, 1968).

Куресса а рески й го р и зон т $\left(\mathrm{K}_{3} \mathrm{a}\right)$ в рассматриваемом разрезе $(67,70-80,40$ м) представлен главным образом глинистыми известня ками и мергелями, в которых установлена особенно богатая ассоциация остракод, состоящая из 30 видов. Наряду с видами широкого вертикального распространения (Amygdalella subclusa Martinsson. Orcofabella obscura Sarv, Cytherellina magna (Neckaja) и др.), большинство встреченных здесь видов имеют большое стратиграфическое значение. Часть их, в том числе Calcaribeyrichia altonodosa Sarv, Hemsiella loensis Martinsson, Clavofabella nodosa Sarv и Limbinariella macroreticulata Sarv, найдена уже в паадласком горизонте, но в основном они распространены в отложениях курессаареского горизонта. Такие виды, как Retisacculus semicolonatus Martinsson, R. sulcatus Gailite, Macrypsilon parvisulcatum Sarv, Beyrichia venusta Sarv, Plicibeyrichia numerosa Sarv, Clavofabella ? lativelata Sarv и Ochesaarina variolaris Neckaja, 


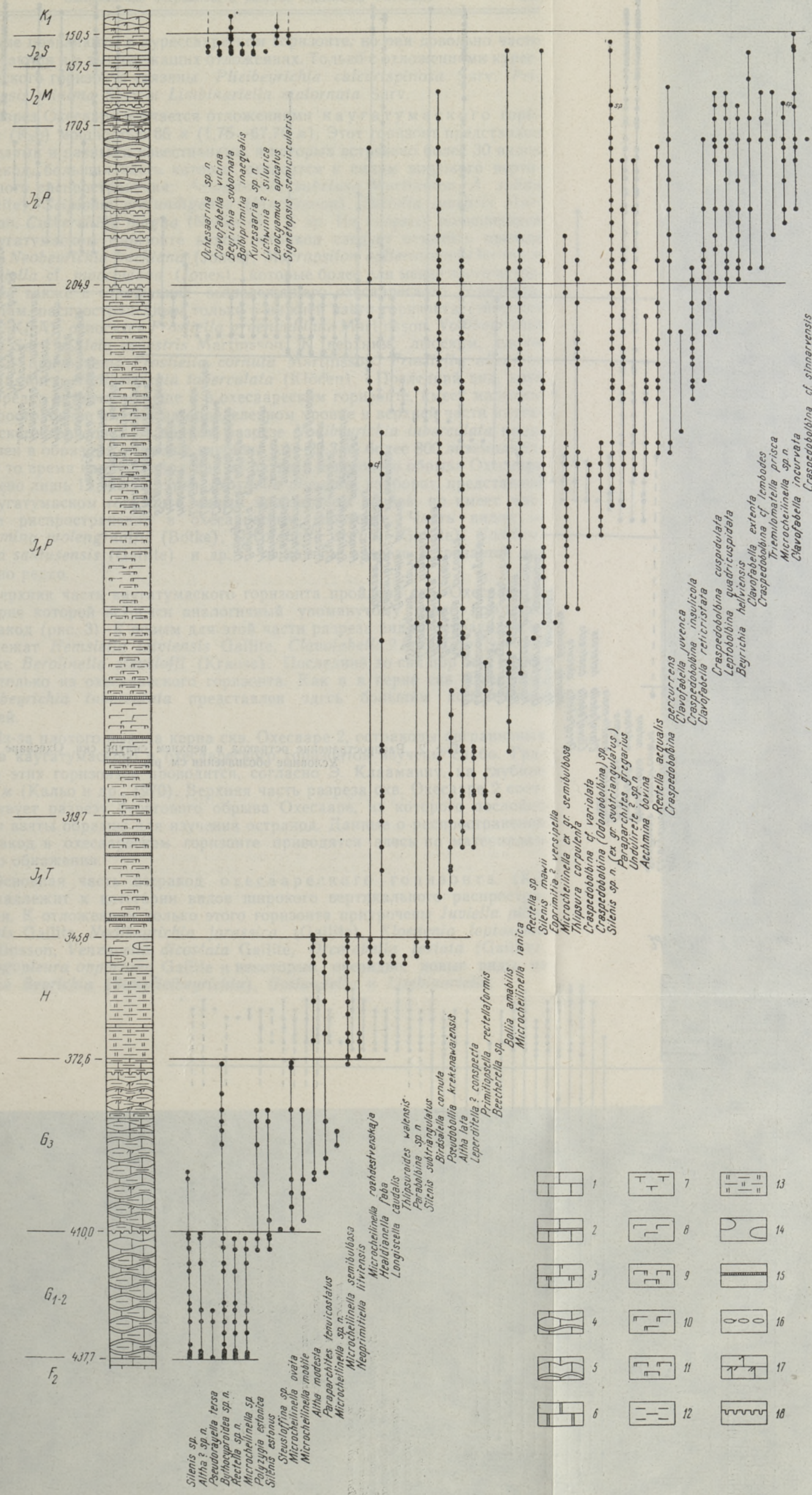

Рис. 1. Распространение остракод в нижнем силуре скв. Охесааре.

1 - известняки; 2 -.. известняки с прослоямн мергеля; 3 - доломитистые или доломитовые известняки; 4 - комковатые извест. няки с тонкими или толстыми прослоями мергеля; 5 - волнистослонстые известняки с тонкими или толстыми прослоями мер-
геля; 6 - доломиты; 7 - мергели; 8 - известковые мергели: 9 - доломитнстые нзвестковые мергели; 10 - долом:Ітовые геля; 6 - доломиты; 7 - мергели; 8 - известковые мергели: 9 - доломитнстые известковые мергели; 10 - доломитствые пород): 1.8 - доломитовые глины: 14 - комки известняков; 15 - прослон метабентонитов; 16 - конгломератовне прсслои: Прерывистые линии обозначают вероятное распространение видов остракод 


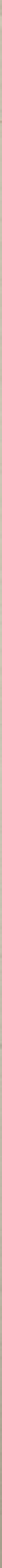

СKB КЛИФ

OXECAAPE 2 OXELAAPE

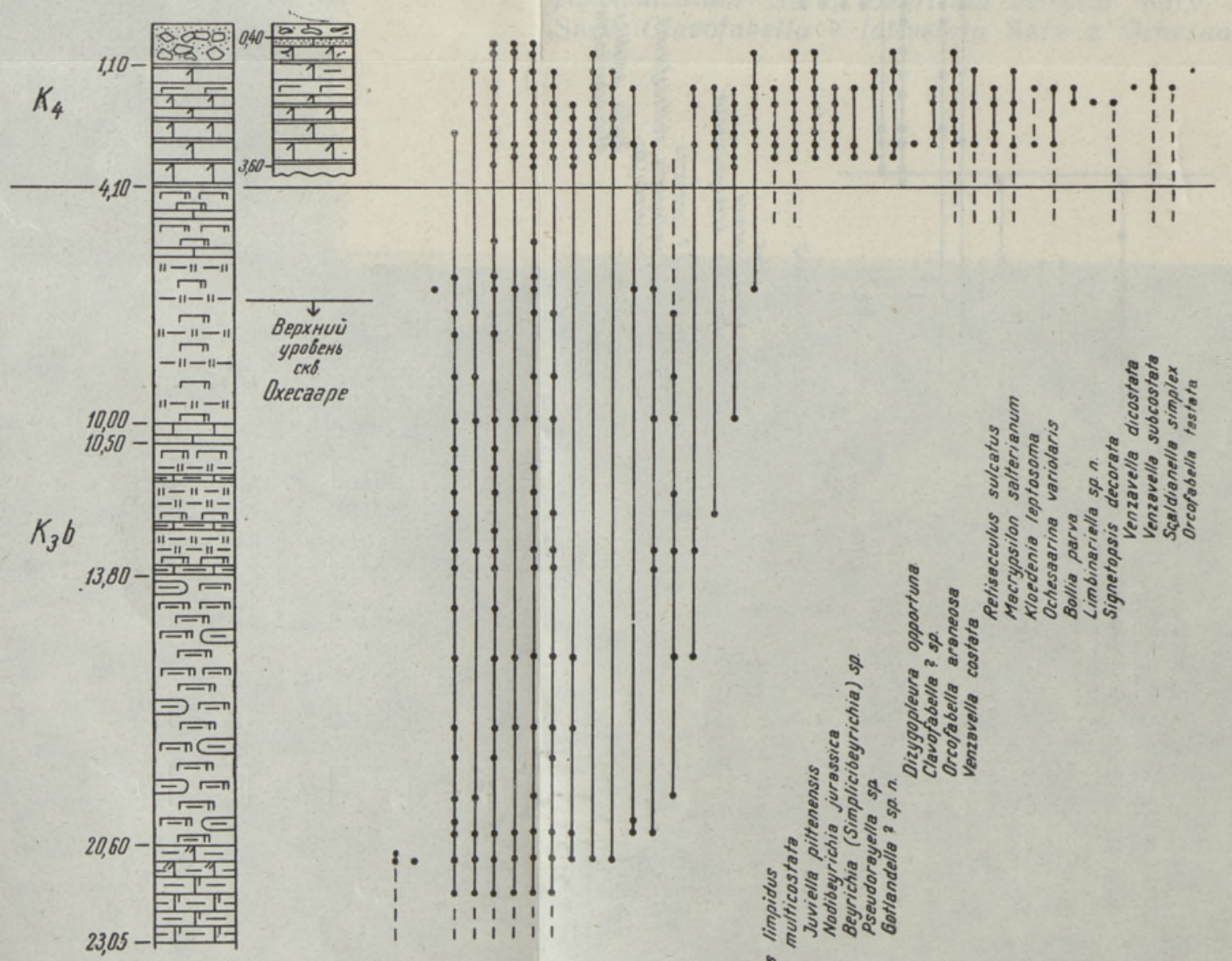

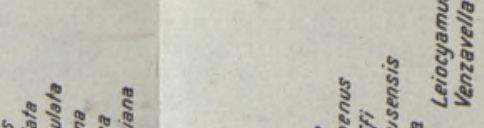

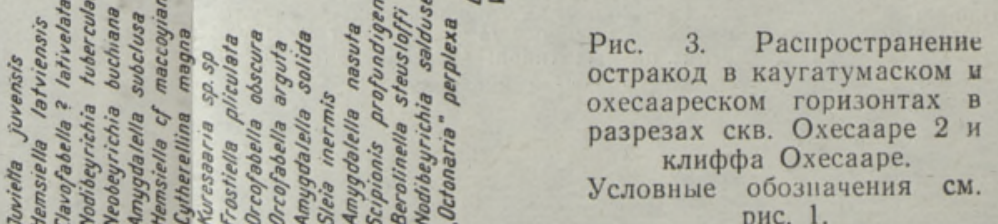
рис. 1. 
впервые появляются в курессаареском горизонте, но они довольно часто встречаются и в вышележащих отложениях. Только с отложениями курессаареского горизонта связаны Plicibeyrichia calcarispinosa Sarv, Primitiopsis minima Sarv и Limbinariella malornata Sarv.

Разрез Охесааре венчается отложениями каугатум а с кого горизонта $\left(\mathrm{K}_{3} \mathrm{~b}\right)$ мощностью $66 \mu(1,75-67,70 \mu)$. Этот горизонт представлен мергелями и разными известняками, в которых встречено более 30 видов остракод, большая часть которых относится к видам широкого вертикального распространения: Amugdalella subclusa Martinsson, A. solida (Gailite). Scipionis profundigenus (Martinsson). Juviella iuvensis Martinsson. Cytherellina magna (Neckaja) и др. Из впервые появившихся в каугатумаском горизонте видов остракод следует отметить прежде всего Neobeurichia buchiana (Jones), Macrupsilon salterianum (.Ionеs) и Hemsiella cf. maccouiana (Jones). которые более или менее часто встречаются также в отложениях вышележашего охесаареского горизонта. К видам, распространенным только в нижней части горизонта (эйгуские слои, $\left.\mathrm{K}_{3} \mathrm{bA}\right)$, относятся Frostiella groenvalliana Martinsson, Nodibeurichia bifida Sarv и Sleia equestris Martinssnп. K верхним, лыоским, слоям (K॰bL) приурочены Frostiella cornuta Martinsson. Frostiella pliculata Martinsson и Nodibeyrichia tuberculata (Klöden). Последний вид, хотя он изредка встречается еще и в охесаареском горизонте, имеет массовое распространение именно на определенном vровне в верхней части каугатумаского горизонта. В данном разрезе Nodibeyrichia tuberculata представлен в образцах, взятых с глубины 2,0-29,3 $м$, более 800 экземплярами. в то время как в 25 образцах из разреза берегового обрыва Охесааре найдено лишь 12 экземпляров. Frostiella pliculata, наоборот, представлен в каугатумаском горизонте малым количеством особей. но имеет массовое распространение в охесаареском горизонте. Часть видов Aechmina molengraaffii (Botke), Orcofabella arguta (Gailite). Nodibeurichia saldusensis (Gailite) и др. - в данном разрезе встречается довольно редко.

Верхняя часть каугатумаского горизонта пройдена скв. Охесааре 2. в керне которой встречен аналогичный упомянутому выше комплекс остракод (рис. 3). К новым для этой части разреза видам остракод принадлежат Hemsiella latviensis Gailite, Clavofabella? lativelata Sarv a также Berolinella steusloffi (Krause). Последний до сих пор был известен только из охесаареского горизонта. Как и в керне скв. Охесааре, Nodibeyrichia tuberculata представлен здссь больши́м количеством особей.

Из-за плохого выхода керна скв. Охесааре 2, остракоды пограничных слоев каугатумаского и охесаареского горизонтов изучены слабо. Граница этих горизонтов проводится, согласно Э. Клааманну, на глубнне 4,10 м (Кальо и др., 1970). Верхняя часть разреза скв. Охесааре 2 соответствует разрезу берегового обрыва Охесааре, из которого послойно были взяты образцы для изучения остракод. Данные о распространении остракод в охесаареском горизонте приводятся здесь по материалам этого обнажения.

Основная часть остракод охеса ареского горизонта $\left(\mathrm{K}_{4}\right)$ принадлежит к категории видов широкого вертикального распространения. К отложениям только этого горизонта приурочены Juviella piltenensis Gailite, Nodibeyrichia jurassica (Gailite), Kloedenia leptosoma Martinsson, Venzavella dicostata Gailite, Orcofabella testata (Gailite), Dizygopleura opportuna Gailite и некоторые, очевидно, новые виды из родов Beyrichia (Simplicibeyrichia), Gotlandella и Limbinariella. 
Из перечисленных видов Kloedenia leptosoma и Dizygopleura opportuna встречены только в определенных слоях и могут служить руководящими видами при более детальной корреляции отложений охесаареского горизонта Прибалтики. Довольно характерным элементом охесаареской ассоциации остракод следует считать еще виды Frostiella pliculata, Berolinella steusloffi и Nodibeyrichia saldusensis, которые появляются уже в каугатумаском горизонте, но имеют именно здесь массовое распространение.

Аналоги каугатумаского и охесаареского горизонтов на о. Готланд отсутствуют (Martinsson, 1967). Согласно распространению Frostiella groenvalliana в слоях Эвед-Рамсоза в Сконе, последние могут соответствовать эйгуским слоям на о. Сааремаа. В Подолии каугатумаскому и охесаарескому горизонтам соответствует скальский горизонт (см. также Абушик, 1968).

Разрез скв. Охесааре целиком охватывает отложения, сформировавшиеся в довольно удаленной от берега части силурийского бассейна. Об этом свидетельствует характер отложений, а также некоторые упомянутые выше особенности в вертикальном распространении остракод. Однако подавляющее большинство общих с областью выхода видов в составе комплексов остракод этого разреза все же сохраняется.

\section{Л И ТЕ Р А Т Р А}

А а лоэ А. О., К а льо Д. Л. 1962. Краткий обзор силурийских отложений в скважине Охесааре (о-в Сааремаа). Труды Ин-та геол. АН ЭССР, Х.

А буши к А. Ф. 1968. К корреляции силурийских отложений Подолии, Прибалтики и Готланда (данные изучения остракод). В сб.: Стратиграфия нижнего палеозоя Прибалтики и корреляция с другими регионами. Вильнюс.

Г а й ли т е Л. К. 1970. Остракоды кулдигской пачки верхнего ордовика Латвии. В сб.: Палеонтология и стратиграфия Прибалтики и Белоруссии, вып. II. Вильнюс.

К альо Д. Л. (ред.) 1970. Силур Эстонии. Таллин.

К р а нд и в ски й В. С. 1963. Фауна остракод силурийских відкладів Поділля. Кіив

С а р в Л. И. 1968. Остракоды Craspedobolbiniidae, Beyrichiidae и Primitiopsidae силура Эстонин. Таллин.

Ц егел ьн юк П. Д. 1969 . Стратиграфия и возраст силурийских и нижнедевонских отложений Приднестровья. Геол. ж., $29,4$.

Martins o n A. 1967. The succession and correlation of ostracode faunas in the Silurian of Gotland. GFF, 89, 3.

Ннститут геологии
Академии наук Эстонской ССР

Поступила в редакцию 24/V 1971

\section{SARV}

\section{OHESAARE PUURAUGU SILURI KIHTIDE OSTRAKOODID}

Käsitletakse Ohesaare puursüdamikust leitud ostrakoodide stratigraafilist levikut. Eristatakse liikide assotsiatsioonid, mis on iseloomulikud ländouveri, uenloki ja ladlou-dauntoni ladejärkudele, ning näidatakse, et eri lademetes esinevad liikide kompleksid on väga lähedased nende lademete paljanditest ning avamusalale lähematest puuraukudest leitud kompleksidele. Mõnede liikide piiratud vertikaalne levik võimaldab nende kasutamist vastavate kihtide korreleerimiseks mitte ainult Baltikumis, vaid ka kaugemal (Podoolia, Gotland). 


\section{SARV}

\section{SILURIAN OSTRACODES IN THE OHESAARE BORING}

The article deals with the stratigraphic distribution of ostracodes in the Ohesaare boring, situated on the west coast of the Sōrve Peninsula, Saaremaa Island. That boring, at an interval of 1.75 to $437.5 \mathrm{~m}$, passes almost entirely through Silurian beds, the uppers of the Kaugatuma Stage (ab. $3 \mathrm{~m})$ and the Ohesaare Stage being missing. So as to get a complete picture, the ostracodes of the uppers of the Kaugatuma Stage were examined as well, in a boring of a lesser depth (Ohesaare 2), and the ostracodes of the Ohesaare Stage in the cliff of Ohesaare.

The stratigraphic distribution of ostracodes is presented in Figs 1, 2 and 3. In broad lines, it may be divided into Llandoverian, Wenlockian and Ludlovian-Downtonian associations.

The Llandoverian as sociation is rather poor in species. In the Juuru Stage $\left(\mathrm{G}_{1-2}\right)$ some new species have been found; one of those, Bythocyproidea sp. n. occurs, besides, in the Raikküla Stage $\left(\mathrm{G}_{3}\right)$. In that last-mentioned stage, there occur more abundantly Silenis estonus, Polyzygia estonica and Microcheilinella mobile. In the Adavere Stage $(\mathrm{H})$, species of a wide vertical distribution predominate, and only in the uppers occur Thlipsuroides walensis and Longiscella caudalis, which are of a limited vertical, but wide horizontal distribution since both are known from the Restev Stage of the Podolian Silurian. In those uppers we may observe an appearance of such species that are typical of the next association, the W e $\mathrm{llock}$ i a $\mathrm{n}$ one (Silenis subtriangulatus, Parabolbina sp. n.). That association embraces 40 species, more than a half being typical of the entire Wenlockian: Silenis subtriangulatus, Altha lata, Birdsalella cornuta, Bollia amabilis, and others. In the lowers of the Jaani Stage $\left(\mathrm{J}_{1}\right)$, only, are distributed Pseudobollia krekenawaiensis, Leperditella? conspecta and Primitiopsella rectellaformis, and in the uppers Clavofabella juvenca and Craspedobolbina insulicola.

The most typical species of the Jaagarahu Stage $\left(\mathrm{J}_{2}\right)$ are Leptobolbina quadricuspidata, Beyrichia hellviensis, Clavofabella extenta, etc. In the uppers, however, a new element appears, headed by Leiocyamus apicatus and Beyrichia subornata.

The Ludlovian-Downtonian association (66 species) in the Ohesaare boring begins to appear in the Paadla Stage $\left(\mathrm{K}_{2}\right)$. The complex of that stage contains 28 species, the most characteristic ones being Hemsiella hemsiensis, Amygdalella paadlaensis, Moorea bisulcata, and others. In the Kuressaare Stage $\left(\mathrm{K}_{3} \mathrm{a}\right)$, exclusively, have been stated Primitiopsis minima, Limbinariella malornata and Plicibeyrichia calcarispinosa, whereas all the other species are of a wider vertical distribution. The Kaugatuma Stage $\left(\mathrm{K}_{3} \mathrm{~b}\right)$ is characterized by Frostiella groenvalliana in the lower, Aigu beds $\left(\mathrm{K}_{3} \mathrm{~b} \AA\right.$ ) and a mass occurrence of Nodibeyrichia tuberculata in the upper, Lõo beds ( $\mathrm{K}_{3} \mathrm{bL}$ ); besides those. there appear, in the stage, Neobeyrichia buchiana, Macrypsilon salterianum and Hemsiella cf. maccoyiana. In the Ohesaare Stage $\left(\mathrm{K}_{4}\right)$, the occurrence of species of a wide vertical distribution continues, with an addition of Nodibeyrichia jurassica, Kloedenia leptosoma, Dizygopleura opportuna, and others, which are typical of that stage.

In recent years, researchers have arrived at more or less the same viewpoints concerning the problem of the correlation of Silurian beds of Gotland, East Baltic and Podolia on the basis of ostracodes (Martinsson, 1967; Abushik, 1968; Sarv, 1968). The distribution of ostracodes in the Ohesaare section serves as a confirmation of the standpoints of the above-mentioned authors. 